\title{
Leaf biomechanical properties in Arabidopsis thaliana polysaccharide mutants affect drought survival ${ }^{\mathrm{i}}$
}

\author{
ORIGINAL ARTICLE
}

\section{${ }^{1}$ Ronald Balsamo, ${ }^{1}$ Merewyn Boak, ${ }^{2}$ Kayla Nagle, ${ }^{3}$ Bela Peethambaran, and ${ }^{2,4}$ Bradley Layton*}

\author{
${ }^{1}$ Department of Biology, Villanova University, Villanova, PA 19085 \\ ${ }^{2}$ Department Chemistry and Biochemistry, The University of Montana, Missoula, MT 59812 \\ ${ }^{3}$ Departmant of Biological Sciences, Division of the Biological Sciences, University of the Sciences, Philadelphia, PA 19104 \\ ${ }^{4}$ Department of Applied Computing and Electronics, The University of Montana, Missoula, MT, 59812
}

\footnotetext{
i This material was supported by the National Science Foundation under Grant No. IOS-0950374.

* Corresponding author:

Bradley Layton

Applied Computing and Electronics

Missoula College The University of Montana

909 South Ave W

Missoula, MT 59802

(406) 243-7865

(406) 243-7899 (fax)

e-mail bradley.layton@umontana.edu.
} 
Keywords: 1) Arabidopsis; 2) xylose; 3) rhamnose; 4) drought tolerance; 5) hemicellulose; 6) polysaccharide mutation

Word count: 3958

1 
2 ABSTRACT

4 Individual sugars are the building blocks of cell wall polysaccharides, which in turn

5 comprise a plant's overall architectural structure. But which sugars play the most

6 prominent role in maintaining a plant's mechanical stability during large cellular

7 deformations induced by drought? We investigated the individual contributions of several

8 genes that are involved in the synthesis of monosaccharides which are important for cell

9 wall structure. We then measured drought tolerance and mechanical integrity during

10 simulated drought in Arabidopsis thaliana. To assess mechanical properties, we designed

11 a small-scale tensile tester for measuring failure strain, ultimate tensile stress, work to

12 failure, toughness, and elastic modulus of 6-week-old leaves in both hydrated and

13 drought-simulated states. Col-0 mutants used in this study include those deficient in

14 lignin, cellulose, components of hemicellulose such as xylose and fucose, the pectic

15 components arabinose and rhamnose, as well as mutants with enhanced arabinose and

16 total pectin content. We found that drought tolerance is correlated to the mechanical and

17 architectural stability of leaves as they experience dehydration. Of the mutants, S096418

18 with mutations for reduced xylose and galactose was the least drought tolerant, while the

19 arabinose-altered CS8578 mutants were the least affected by water loss. There were also

20 notable correlations between drought tolerance and mechanical properties in the

21 diminished rhamnose mutant, CS8575 and the dehydrogenase-disrupted S120106. Our

22 findings suggest that components of hemicellulose and pectins affect leaf biomechanical 
1 properties and may play an important role in the ability of this model system to survive 2 drought. 


\section{INTRODUCTION}

4 In this study, we measured several biomechanical properties as well as electrolyte

5 leakage in several Arabidopsis thaliana strains with known mutations in genes related to

6 polysaccharide synthesis that affect cell wall structural integrity

7 Leaf mechanical properties are an indicator of survival during environmentally

8 induced water loss. This cell mechanics - dehydration relationship has been confirmed in

9 drought tolerant species such as Ceanothus (Vincent 1983; Balsamo et al. 2003), drought

10 and desiccation-tolerant Eragrostis grasses (Balsamo et al. 2003; Balsamo et al. 2005;

11 Balsamo et al. 2006) and desiccation-tolerant Polypodium ferns (Layton et al. 2010), but

12 has yet to be studied in Arabidopsis thaliana (Pigliucci 2002).

13 The mechanical integrity of plant leaves that have experienced environmentally

14 induced water loss also show changes at the cellular and subcellular level (Burgert 2006;

15 Milwich et al. 2006; Popper 2008; Layton et al. 2010). Thus, the architecture of cell walls

16 and cell-to-cell adhesions via pectins have a direct impact on leaf mechanical properties

17 and consequently overall organ mechanical stability (Balsamo et al. 2003).

18 While cellulose structure is relatively simple (1,4-linked $\beta$-D-glucose residues

19 forming microfibrils) (Zykwinska et al. 2005), there are multiple types of hemicelluloses

20 (e.g. xylan and xyloglucan) (Peña et al. 2004; Polizeli et al. 2005; Park and Cosgrove

21 2012) as well as pectins, HGA, RG I, and RG II (Zablackis et al. 1995). The primary

22 monosaccharides present in cell walls are D-glucose, D-galactose, D-mannose, D-xylose,

23 L-arabinose, L-fucose, L-rhamnose and D-galacturonic acid (Popper 2008). 
1 Cell wall mechanical properties are also impacted by saccharide components of

2 cellulose, hemicelluloses and pectin that may contribute directly to mechanical strength

3 (Zablackis et al. 1995; Polizeli et al. 2005). For example, galactose residues of

4 xyloglucan impact the effectiveness of hemicellular binding of cellulose microfibrils, and

5 subsequently mechanical strength in cell walls (Peña et al. 2004). Additionally, a variety

6 of neutral sugar sidechains (including arabinose and galactose) allow pectin components

7 to crosslink to cellulose microfibrils, enhancing mechanical strength, while pectins

8 without these sidechains are unable to bind (Zykwinska et al. 2005). Mechanical strength

9 may also be impacted by the galactosinated sidechains of xyloglucan, while the

10 fucosilated sidechains may be less important (Ryden et al. 2003).

11 While wild type Arabidopsis, while not drought-tolerant, has been sequenced and

$12 \sim 10 \%$ of its genes affect cell wall physiology and development (Geitmann 2006; Taiz and

13 Zeiger 2006). Arabidopsis also offers a variety of single- and multiple-gene mutants with

14 altered cell wall monosaccharide compositions, making it a useful model for drought

15 studies.

16 This original study reports the differences among mechanical properties of

17 Arabidopsis leaves resulting from dehydration. It is the first attempt to relate these

18 measurements to drought tolerance in eight mutants that overexpress, underexpress or

19 otherwise disrupt specific cell-wall monosaccharides. Control and experimental groups

20 were grown under fully hydrating and partially dehydrating conditions then destructively

21 tensile-tested to reveal how drought affects mechanical properties and survivability.

METHODS \& MATERIALS 
1 Overview-We grew an assortment of Arabidopsis mutant lines with known

2 deficiencies in specific monosaccharides. These are described under methods of growth

3 conditions and drought simulations and summarized in Table 1. 
1 Table 1. Mutants selected for their role in monosaccharide-related alterations. CS=Chris

2 Sommerville; JV=John Vogel, SS= Shauna Somerville; CC=Clint Chapple, WDR=Wolf-Dieter

3 Reiter, DC=David Cavalier, KK=Ken Keegstra, JE=Joseph Ecker; EMS=ethyl

4 methanesulfonate.

\begin{tabular}{|c|c|c|c|c|c|}
\hline mutant & $\begin{array}{l}\text { polymorph/ } \\
\text { locus }\end{array}$ & $\begin{array}{l}\text { donor/ } \\
\text { origin }\end{array}$ & Phenotype & mutagen & ref \\
\hline \multirow[t]{2}{*}{ CS3094 } & At5g48300 & $\mathrm{CS}$ & $\downarrow$ maltose, starch & EMS & (Lin et al. 1988) \\
\hline & & & $\downarrow$ xylose and fucose & & \\
\hline CS6354 & At3g54920 & JV, SS & $\begin{array}{c}\text { 个 pectin } \\
\text { altered cellulose } \mathrm{H} \text {-bonding }\end{array}$ & EMS & (Vogel et al. 2002) \\
\hline CS8575 & mur8-1 & CC, CS, WDR & $65 \% \downarrow$ leaf rhamnose & EMS & (Reiter et al. 1997) \\
\hline CS8578 & $\begin{array}{l}\text { At5g17420 } \\
\text { (MUR10-2) }\end{array}$ & CC, CS, WDR & $\begin{array}{c}\uparrow \text { arabinose in cell wall; } \\
\uparrow \text { arabinan:galactan ratio } \\
\downarrow \downarrow \text { fucose, xylose, } \\
\text { arabinose, mannose and } \\
\text { galactan }\end{array}$ & EMS & (Reiter et al. 1997) \\
\hline CS8579 & mur11 & CC, CS, WDR & $\begin{array}{c}\downarrow \text { rhamnose, fucose, } \\
\text { xylose } \\
\uparrow \text { mannose }\end{array}$ & EMS & (Reiter et al. 1997) \\
\hline CS16349 & $\begin{array}{l}\text { At3g62720 } \\
\text { At4g02500 }\end{array}$ & $\mathrm{DC}, \mathrm{KK}$ & $\begin{array}{c}\text { disrupts xylose transferase } \\
\text { which decreases } \\
\text { UDP-xylose }\end{array}$ & T-DNA & (Faik et al. 2002) \\
\hline S038620 & At5g54690 & JE & $50 \% \downarrow x y l o s e$ & T-DNA & (Alonso et al. 2003) \\
\hline S096418 & At5g15630 & JE & $40 \% \downarrow$ galactose & T-DNA & (Alonso et al. 2003) \\
\hline
\end{tabular}




\begin{tabular}{llccc}
\cline { 2 - 4 } S120106 & At2g40410 & JE & possible mannitol & T-DNA (Alonso et al. 2003) \\
& At2g40400 & & dehydrogenase disruptionii & \\
\cline { 2 - 5 } S144144 At1g78860 & JE & possible mannose & T-DNA (Alonso et al. 2003) \\
& & & binding disruption &
\end{tabular}

1 Mutant selections were based upon literature review and availability, with the

2 majority provided by The Arabidopsis Information Resource, Ohio State University

3 (TAIR 2009). Plant lines selected were Col-0 controls, monosaccharide mutants

4 (arabinose, fucose, galactose, glucose, mannose, rhamnose, or xylose), or complex plant

5 cell-wall mutants (Zablackis et al. 1995; Reiter 2002; Peña et al. 2004; Zykwinska et al.

6 2005; Rösti et al. 2007; Popper 2008). All seeds purchased from TAIR were homozygous

7 to t-DNA insertions. An extensive search of available cell-wall related mutants found that

8 a number of the key monosaccharides (galactose, mannose, and xylose) were not

9 represented in altered concentration mutant lines, but were instead available only as

10 t-DNA insertion lines created at the Salk Institute, which have not been as extensively

11 tested and thus have monosaccharide alterations that are less well understood (Alonso et

12 al. 2003). The Reiter laboratory had generated a number of altered cell wall

13 monosaccharide mutants, most of which were utilized in this project, as were altered

14 starch concentration mutants (as a proxy for glucose) from the Somerville laboratory

15 (Caspar et al. 1988; Lin et al. 1991; Reiter et al. 1997).

16 In each of the experimental groups (Table 1), either ethyl methanesulfonate or t-DNA

17 insertion created the original lines, with t-DNA being the lesser preferred because of the

18 increased potential for additional unrelated mutations (Radhamony et al. 2005).

ii Personal communication with George Lindsay. 
1 Growth conditions-Seeds in 20- to 30-seed batches were treated in three 30-second

2 baths of $400 \mu 15 \%$ Clorox solution (vortexing each bath) to remove mold or fungus,

3 followed by three 30-second baths in $400 \mu 1$ 100\% ethanol to remove Clorox residue, and

4 three 30-second baths in deionized water to remove ethanol residue. Each batch of seeds

5 was transferred to a $250 \mathrm{ml}$ culture plate $(4.4 \mathrm{~g} / \mathrm{L})$ Murashige and Skoog salts

6 (GIBCO/BRL) with Gamborg's vitamins (Sigma-Aldrich, St. Louis, Missouri) $6 \mathrm{~g} / \mathrm{L}$ agar,

7 pH 5.8. (Sigma-Aldrich) and deionized water (Taylor et al. 1999; Vogel et al. 2002;

8 Cavalier et al. 2008; Lindberg et al. 2012). Labware was autoclaved at $121^{\circ} \mathrm{C}$ for $30 \mathrm{~min}$

9 to ensure an aseptic germination environment. Plates were taped, covered, and cold-

10 treated at $4^{\circ}$ Celsius $\sim 72$ hours (NASC 2009; Purdue 2009). Plants were germinated on

11 culture plates. After five days, plates were uncovered, and transferred to enclosed growth

12 chamber for two weeks, after which seedlings were transferred to soil (Salinas and

13 Sanchez-Serrano 2006).

14 Seedlings were grown in Pro-Mix PGX or MetroMix Redi-earth (perlite/vermiculite

15 topsoil/peat mixes). This was augmented with $25 \% 0.2$ to $0.5 \mathrm{~cm}$ diameter calcined clay

16 granules (porous ceramic) to regulate water retention, a Miracle Grow slow-release

17 fertilizer pellet (15-9-12), and imidacloprid (Marathon $1 \mathrm{G}$, an insecticide) at $4.2 \mathrm{~kg} \mathrm{~m}^{-3}$

18 (about 0.25 teaspoon per pot). The soil mixture was autoclaved twice prior to use. 6" $\times 3$ "'

$19 \times 3$ " plastic containers with drainage openings (three $2 " \times 3$ " compartments) were filled

20 with the augmented soil mixture, which was thoroughly moistened and allowed to drain.

21 Two seedlings were transferred to each compartment, such that each seedling had

22 approximately $1 " \times 1.5 " \times 3$ ", with a total of 18 seedlings per plant type transplanted.

23 Pots were maintained in 21 to $23^{\circ} \mathrm{C}$ growth chambers during March to December, with 
1 24-hour continuous exposure to 100 to $120 \mu \mathrm{mol} \mathrm{m}^{-2} \mathrm{~s}^{-1}$ using Conviron A1000

2 (Pembina, SD) 50\% humidity. As plants developed they were bottom-watered (placed in

3 one inch of standing water and left for no longer than $30 \mathrm{~min}$ ) every two days, to prevent

4 damage to aboveground tissue and root stress. Water was also applied via a spray bottle

5 daily. Plants were covered with a non-airtight clear plastic lid for the first two weeks

6 following transplantation to promote survival rates. At the end of five weeks of

7 greenhouse conditions, drought simulations began. This period lasted one week and

8 plants were harvested.

9 Drought Simulation-After harvest, mechanical and conductivity experiments were

10 conducted. The measure of electrolyte leakage is an established technique for assessing

11 cellular damage and thus drought tolerance for each experimental group (Tinus 2002;

12 Rolny et al. 2011).

13 Mechanical Measurements-Five mechanical properties of rosette leaves were

14 measured. Whole leaves were excised for tensile strength measurements. The mass of

15 each leaf $( \pm 0.001$ gram $)$ was recorded on Sartorius GCA2502 Milligram Balance

16 (Goettingen, Germany). Fowler ProMax digital caliper (Newton, Massachusetts) was

17 used to measure the length (along the midrib), the width (across the widest point of the

18 leaf), and the thickness (at the base of the leaf, across the petiole), \pm 0.01 millimeter.

19 Although the width varied, rather than attempt to invent an arbitrary and complicated

20 metric, we chose the widest point as a standard. The length was used to determine the

21 displacement rate in $\mu \mathrm{m} \mathrm{s}^{-1}$ to maintain strain rate of 0.004 to $0.005 \mathrm{~s}^{-1}$ for viscoelastic

22 composite materials (ASTM D 3039 and ASTM D 412) (Davis 2004), resulting in

23 displacement rates 20 to $80 \mu \mathrm{m} \mathrm{s}^{-1}$. To minimize boundary effects, we clamped each leaf 
1 such that half of the total length served as the gage length (Figure 1). For example, a 25-

$2 \mathrm{~mm}$ leaf has a gage length of $12.5 \mathrm{~mm}$. Thus, $12.5 \mathrm{~mm} \cdot 0.005 \mathrm{~s}^{-1}=62.5 \mu \mathrm{m} \mathrm{s}^{-1}$. This

3 number was then rounded to the nearest $10 \mu \mathrm{m}$, in this case, $60 \mu \mathrm{m} \mathrm{s}^{-1}$. A Hewlett

4 Packard 34401-A multimeter was attached to a Mastech HY5002 DC power supply, a

5 Dell Optiplex GX240 computer, and a custom-built tensile testing apparatus with an

6 Omega 113 gram sensor and an Omegabus D1521 transmitter. The leaf was placed in a

7 padded clamp perpendicular to the midrib, which was screwed into the top of the load

8 sensor attached to a platform. A second clamp was attached at the opposite tip of the leaf

9 such that the chord lengths within the clamps were approximately equal and one-half of

10 the leaf served as the staple length. The second clamp was attached to a vertical pull bar,

11 which was rotated upwards at a precalculated rate (in the example above, $60 \mu \mathrm{m}$ per

12 second), applying force to the leaf (gravitational forces were neglected). The force was

13 registered by the load sensor, translated through the multimeter, and sent to the computer,

14 where it was recorded by a custom-written Labview VI (National Instruments LabVIEW

$15 \mathrm{v}$, Austin, Texas) and translated from microvolts to $\mathrm{mN}$. Measurements were taken

16 every $0.3 \mathrm{~s}$ as force was applied until failure, after which the largest recorded

17 measurement was divided by the average cross-sectional area of the leaf between the

18 clamps in order to generate the tensile strength measurement (Balsamo et al. 2003;

19 Layton and Sastry 2006). Leaf width and thickness prior to testing were used to calculate

20 the surface area, which was then divided by the maximum failure load in millinewtons

$21(\mathrm{mN})$ generated during the test to provide the tensile strength for that leaf in megapascals

22 (MPa). Work to failure, $W$ was found by numerical integration under generated force-

23 displacement curves. Toughness or volume-specific energy density, $W_{\mathrm{V}}$ was calculated 
1 by dividing the work to failure in $\mathrm{mJ}$ by the gage volume in $\mathrm{mm}^{3}$. Elastic modulus was

2 determined heuristically by individually inspecting every stress-strain curve and selecting

3 a low datapoint where the upward curvature of the stress-strain curve became negligible,

4 and a high datapoint where downward curvature became prevalent and calculated as

$5 E=\left(\sigma_{\mathrm{H}}-\sigma_{\mathrm{L}}\right) /\left(\varepsilon_{\mathrm{H}}-\varepsilon_{\mathrm{L}}\right)($ Figure 2$)$.

6 Drought Tolerance Conductivity Measurements-Levels of dehydrative insult were

7 assessed by electrolyte leakage as a measure of irreversible tissue damage (Tinus 2002;

8 Peng et al. 2010). Conductivity measurements were performed using an EP11/pH pDS

9 meter (Myron L. Company, Carlsbad, California). After calibrating the meter with a

10 standard conductivity solution (Myron L. Company), the sensor and sensor well were

11 rinsed three times with deionized water. Rosette leaf samples were excised with a $6.4 \mathrm{~mm}$

12 diameter cork borer for leaf samples (Sigma-Aldrich). $10 \mathrm{ml}$ of Milli-Q water added to a

$1325 \mathrm{ml}$ glass sample bottle with one leaf sample, and the bottle gently agitated for 10

14 minutes. The water and leaf sample were transferred to the meter's sensor well with care

15 to ensuring that the liquid covered the sensor. The sensor well was rinsed and dried twice

16 between each reading with deionized water.

17 Statistical analyses - Conductivity readings (one per leaf) were performed to assess

18 membrane stability as an indicator of cell damage and thus drought tolerance on leaves

19 from both of the experimental groups: mutant hydrated (MH) and mutant dehydrated

20 (MD). The highest and lowest readings of the 17 taken were discarded, and the average

21 and standard error of the remaining 15 was taken for as the trimmed mean for each

22 treatment of each of the four experimental groups. This mechanical testing described

23 above was also repeated on a total of 17 leaves per plant type, with the highest and lowest 
1 measurements being excluded, and the remaining 15 being averaged for each of the five

2 mechanical properties measured to give a value for each experimental group according to

3 previously established methods (Balsamo et al. 2005; Balsamo et al. 2006; MacMillan et

4 al. 2010). All data were then tested via ANOVA and followed with a post hoc test 5 (Tukey's HSD) using SPSS 21.0.0 software.

\section{RESULTS}

7 In mutant specimens the work to failure in the hydrated state was diminished 8 compared to controls. With two exceptions, CS8575 and CS6354, this was also true of 9 the dehydrated state. This indicates that mutants had diminished the total cell wall mass.

10 In contrast, most mutants had toughness values that were either greater in the hydrated

11 state or dehydrated state, but rarely both, indicating that what structural material is

12 present is still intact and capable of sustaining mechanical loads. Notably, all but one of

13 the mutants selected for this study had tensile strengths greater than controls in the

14 dehydrated state, but comparable tensile strengths in the hydrated state. This was likely

15 caused by the relatively diminished leaf cross-sectional areas. As expected the two

16 mechanical properties that were affected most by drying were tensile strength and

17 toughness since both use cross sectional area in the calculation, which was significantly

18 diminished in the dehydrated state.

19 Statistical analyses - The post hoc test (Tukey's HSD) yielded a set of groupings for

20 the conductivity tests and each of the five mechanical tests (Table S1). Notable is that the

$21 W$ in the wildtype specimens was greatest. Each of the results from the mutants are

22 described in more detail below. 
1 Mutant CS6354 is a xylose- and fucose-deficient mutant, with increased pectin

2 (Vogel et al. 2002). Our results revealed substantially worse drought resistance

3 (P < 0.0001) (Fig S1A). This mutant, unlike the controls, had enhanced $W$ in the dry state

4 (Fig 3D). Overall, since fucose appears to have a general stiffening nature and xylose

5 tends to have a generally compliant nature, the deficiency of both had a neutral effect.

6 Mutant CS8575 has been recorded to express reduced rhamnose (65\% of wild-type)

7 (Reiter et al. 1997). In the present study its leaves exhibited the greatest tensile modulus

8 of any hydrated plant and an elevated tensile strength (Fig 3A). While its survivability as

9 measured by conductance was statistically equivalent to the controls, its leaves in the

10 hydrated state had the lowest average failure strain value (Fig 3C). Perhaps most notable

11 was that it had the greatest $W$ under drought conditions, but significantly diminished $W$ in

12 the hydrated state. Finally, $W_{\mathrm{V}}$ was enhanced in the dry state (Fig 3E). CS8575's $E$ and $\varepsilon_{\mathrm{f}}$

13 were relatively unaffected (Fig 3A, 3C).

14 Mutant CS8578 expresses increased arabinose in cell walls (Bosca et al. 2006). This

15 mutant had the lowest conductance (greatest survivability) of all mutants and sugar-

16 treated plants (Fig S1A) $(\mathrm{P}<0.010)$. It also had the greatest failure strain, and toughness

17 in both the hydrated and dehydrated states of any of the mutants (Fig S1D, S1F). Its

18 modulus was second lowest among mutants, whereas its tensile strength was elevated.

19 Mutant CS8579 is a rhamnose, fucose, and xylose-deficient line with enhanced

20 mannose and decreased xyloglucan. These specimens exhibited among the lowest

21 conductances (greatest survivability) and the greatest tensile strength in the dry state,

22 which is consistent with our hypothesis that enhanced survivability correlates with

23 enhanced mechanical properties. It had the second greatest tensile modulus in the 
1 hydrated state, whereas the failure strain was similar to that in control plants. This

2 mutant's $W$ was among the smallest for both the hydrated and dehydrated states. Its

3 toughness in both the hydrated and dehydrates states was greater than those of control

4 values $(\mathrm{P}<0.05)$. Morphologically, it exhibited notably large leaves with purple abaxial

5 surfaces.

6 Mutant CS16349, with disruptions in xylose transferase and diminished UDP-xylose,

7 exhibited increased conductance (Fig S1A). It was one of two to exhibit a greater tensile

8 modulus in hydrated versus dehydrated state (Fig S1B), which might be related to

9 hydrophilicity of specific sugars. Failure strain was significantly less in hydrated samples

10 versus dehydrated samples (Fig S1D). Mutant 16349 also had the lowest tensile strengths,

11 as well as modest work to failure and toughness (Fig S1E, S1F).

12 Mutant S038620 has been observed to be xylose deficient by 50\% (Alonso et al.

13 2003). This mutant had the greatest tensile modulus $(\mathrm{P}<0.05)$ in the dehydrated state and

14 the lowest work to failure and failure strain ( $p<0.01$ for dehydrated) (Fig S1). This

15 brittle behavior was as anticipated, based upon the biomechanical role that xylose is

16 known to play. Toughness values were similar to those of the wildtype (Fig S1F).

17 Mutant S096418 exhibits a reduction in galactose of 60\% (Alonso et al. 2003). It had

18 the worst drought tolerance as indicated by its highest ranking conductance value

19 (p < 0.005) (Fig S1A). Its tensile modulus in the hydrated state was the lowest overall

$20(\mathrm{p}<0.005)($ Fig S1B), as was its toughness value in the dehydrated state $(\mathrm{p}<0.005)$

21 (Fig S1F). Failure strain was greater in the hydrated $(\mathrm{p}<0.005)$ versus dehydrated plants

$22(\mathrm{p}<0.05)$ (Fig S1D). Similarly to the effects of enhanced galactose, this galactose- 
1 deficient mutant had very poor survivability but relatively unaffected mechanical

2 properties, indicating a plausible role in metabolism and signaling.

3 Mutant S120106 is a mannitol dehydrogenase mutant line from the Salk laboratory

4 (Alonso et al. 2003). Hydroxyl groups are replaced with hydrogen and mannose

5 intercalates into lignin milieu. Conductance measures were similar to those of controls

6 (Fig S1A). This mutant had the lowest tensile modulus with the second greatest failure

$7 \quad$ strain and a relatively high $W$ (Figs S1B, S1D, S1E). Enhanced mannose in lignin should

8 stiffen tissue, whereas the altered mannose of this line should reduce the modulus.

9 However, since lignin is not a major component in leaves, the modest changes we

10 observed were expected.

\section{DISCUSSION}

12 Cell walls, which are composed of the polysaccharide components cellulose,

13 hemicelluloses, and pectins, provide mechanical support for plants (Reiter et al. 1993).

14 Our previous studies have shown that species or specimens that exhibit drought or

15 desiccation tolerance typically also exhibit enhanced biomechanical properties (Balsamo

16 et al. 2003; Balsamo et al. 2003; Balsamo et al. 2005). However, this is the first study of

17 its kind to seek the individual mechanical properties of failure strain, tensile strength,

18 modulus of elasticity, work to failure, and toughness in a genetically altered organism

19 undergoing drought.

20 Rhamnose features prominently as a component in two of the three primary pectic

21 polysaccharides: rhamnogalacturonan I and II and CS8575 mutants with reduced

22 rhamnose fared better under drought conditions. 
1 Galactose is part of the hemicellular matrix. It is represented in a variety of cell wall

2 structures, including galacturonic acid in pectin, assorted other pectic structures, as a

3 component of arabinogalactan proteins, and as a possible side chain on mannans or

4 xylans. Quantification of cell wall components suggests that galactose is the second most

5 common neutral monosaccharide regardless of leaf age or Arabidopsis ecotype.

6 Furthermore, galactose-containing sidechains of xyloglucan make a major contribution to

7 wall strength (Ryden et al. 2003). This may help explain the brittle failure behavior of

8 S096418 in the hydrated state. Galactose is also very similar structurally to glucose and

9 thus might have also been in close competition for signaling as well as uptake during

10 polysaccharide assembly.

11 Mannose is present as a small percentage of a variety of cell wall and tissue types in

12 Arabidopsis, mostly in the form of mannans in lignified secondary xylem cell walls.

13 Mannose is recognized by hexokinase-II, which is a conserved eukaryotic glucose sensor

14 that phosphorylates the C6 on 6-carbon sugars. It is also a small constituent in lignified

15 tissue. Lignin has been measured to comprise approximately $3 \%$ of Arabidopsis leaves by

16 wet mass (Hedderson et al. 2009). As expected, there is also a positive correlation

17 between the lignin per unit cross-sectional area in leaves and tensile strength under fully

18 hydrated conditions (Hedderson et al., 2009).

19 Arabinose contributes to cell wall component structure as it is linked to pectic

20 components, hemicellulose side chain sugars, and in a variety of glycoproteins, including

21 extensions and extracellular arabinogalactan cell surface proteins, which mediate

22 discourse between the cell cytoplasm and cell wall (Cosgrove 2005). The

23 arabinose-enhanced 8578 mutant exhibited high survivability to drought. This apparent 
1 causality of enhanced mechanical properties conferring enhanced survivability supports

2 our overall hypothesis.

3 Fucose features most prominently as a possible hemicellulose side chain or fucosyl

4 pectic component, and accounts for the smallest percentage of the neutral

5 monosaccharides in cell wall components. Mutants deficient in L-fucose were dwarfed in

6 growth and had fragile cell walls, consistent with the findings of (Reiter et al. 1993). One

7 explanation for this is that fucose redirects metabolic energy in its conversion to glucose,

8 with the overall effect of diminished fitness.

9 Xylose is one of the most prevalent of the neutral monosaccharide contributors to the

10 primary and secondary cell wall components, and is found most notably in the

11 hemicelluloses xyloglucan and xylan, and as a pectic component sidechain sugar.

12 Furthermore, plants that are desiccation tolerant make xylose as they are dehydrating. It

13 is a flexible X-linker xyloglucan that relaxes cell walls (Vicré et al. 2004). Overall we

14 observed this effect with the diminished moduli and UTS values, accompanied by large

15 failure strain values.

16 At $167 \mathrm{mM}$, glucose has been shown to maximally affect transcription of

17 ABA-related genes compared to control or higher glucose levels (Price et al. 2004).

18 Glucose affects a broad range of genes, from stress responses and cellular metabolism to

19 those involved in signaling and gene regulation, but its effects are relatively independent

20 of nitrogen status (Price et al., 2004).

21 In addition to the experimental conditions used in this study, other independent

22 factors that may have led to the differences among mechanical properties we measured

23 may include differing levels of expansin in the leaves or the distribution of turgor 
1 pressure itself within the leaf structure (Cho and Cosgrove 2000). Our election to use the

2 widest portion of the leaf as our width measurement likely caused a minor underestimate

3 of stress, and thus an underestimate of modulus and toughness. Another independent

4 factor that may have led to differences in water loss may have been varying degrees of

5 evapotranspiration among the experimental groups that may have occurred during the

6 growing cycle.

7 These studies have demonstrated the importance of cellulose and non-cellulose

8 associated monosaccharides such as hemicellulose and pectic components to the

9 mechanical integrity of the plant cell wall during volumetric water loss. Both genetic

10 predisposition and environmental factors contribute to the ability survive episodic

11 drought in the model system Arabidopsis thaliana. Further work is needed to see if the

12 results found in this study are applicable to agriculturally and an ecologically relevant 13 species.

\section{ACKNOWLDEGMENTS}

17 The authors thank Eric Wall for his assistance in reference gathering, Emily Sterbis for

18 her help with data formatting, Ray Callaway for his help with SPSS, and Brent Boyd and

19 Andrew Bohl for designing the tensile testing equipment and Labview interface. 


\section{LITERATURE CITED}

3 Alonso, J. M., Stepanova, A. N., Leisse, T. J., Kim, C. J., Chen, H. M., Shinn, P.,

4 Stevenson, D. K., Zimmerman, J., Barajas, P., Cheuk, R., Gadrinab, C., Heller,

5 C., Jeske, A., Koesema, E., Meyers, C. C., Parker, H., Prednis, L., Ansari, Y.,

6 Choy, N., Deen, H., Geralt, M., Hazari, N., Hom, E., Karnes, M., Mulholland, C.,

7 Ndubaku, R., Schmidt, I., Guzman, P., Aguilar-Henonin, L., Schmid, M., Weigel,

8 D., Carter, D. E., Marchand, T., Risseeuw, E., Brogden, D., Zeko, A., Crosby, W.

9 L., Berry, C. C., Ecker, J. R. 2003. Genome-wide Insertional mutagenesis of $10 \quad$ Arabidopsis thaliana. Science 301(5633), 653-657.

11 Balsamo, R., van der Willigen, C., Boyko, W., Farrant, J. 2005. Anomalous leaf tensile 12 properties during dehydration may help elucidate mechanisms of desiccation 13 tolerance in Eragrostis nindensis. Physiologia Plantarum 124(336-342), 336-342.

14 Balsamo, R., van der Willigen, C., Farrant, J. 2003. Relating leaf tensile properties to 15 drought and desiccation tolerance for selected species of Eragrostis. 4th 16 International Plant Biomechanics Conference. Michigan State University, 17 Lansing, MI USA: 17-20.

18 Balsamo, R. A., Bauer, A. M., Davis, S. D., Rice, B. M. 2003. Leaf biomechanics, 19 morphology, and anatomy of the deciduous mesophyte Prunus serrulata 
3 Balsamo, R. A., Willigen, C. V., Bauer, A. M., Farrant, J. 2006. Drought tolerance of 4 selected Eragrostis species correlates with leaf tensile properties. Annals of 5

6 Bosca, S., Barton, C. J., Taylor, N. G., Ryden, P., Neumetzler, L., Pauly, M., Roberts, K., 7

(Rosaceae) and the evergreen sclerophyllous shrub Heteromeles arbutifolia (Rosaceae). American Journal of Botany 90(1), 72-77.

$$
\begin{aligned}
& \text { Seifert, G. J. 2006. Interactions between MUR10/CesA7-dependent secondary } \\
& \text { cellulose biosynthesis and primary cell wall structure. Plant Physiology 142(4), } \\
& \text { 1353-1363. }
\end{aligned}
$$

Burgert, I. 2006. Exploring the micromechanical design of plant cell walls. American Journal of Botany 93, 1391-1401.

Caspar, T., Lin, T., Kakefuda, G., Benbow, L., Preiss, J., Somerville, C. 1988. Isolation and characterization of a starchless mutant of Arabidopsis thaliana (L.) Heynh lacking adp-glucose pyrophosphorylase activity. Plant Physiology 86, 1131-1135.

Cavalier, D., Lerouxel, O., Neumetzler, L., Yamauchi, K., Reinecke, A., Freshour, G., Zabotina, O., Hahn, M., Brgert, I., Pauly, M., Raikhel, N., Keegstra, K. 2008. Disrupting two Arabidopsis thaliana xylosyltransferase genes result in plants deficient in xyloglucan, a major primary cell wall component. The Plant Cell $20(6), 1519-1537$.

Cho, H.-T., Cosgrove, D. 2000. Altered expression of expansin modulates leaf growth and pedicel abscission in Arabidopsis thaliana. Proceedings of the National Academy of Science of the United States of America 97(17), 9783-9788. 
1 Cosgrove, D. 2005. Growth of the plant cell wall. Nature Reviews: Molecular Cell Biology 6, 850-861.

3 Davis, J. 2004. Tensile testing. Materials Park, Ohio, ASM International.

4 Faik, A., Price, N. J., Raikhel, N. V., Keegstra, K. 2002. An Arabidopsis gene encoding an alpha-xylosyltransferase involved in xyloglucan biosynthesis. Proceedings of the National Academy of Sciences of the United States of America 99(11), 77977802.

8 Geitmann, A. 2006. Plant and fungal cytomechanics: quantifying and modeling cellular architecture. Canadian Journal of Botany 84, 581-593.

10 Hedderson, N., Balsamo, R., Cooper, K., Farrant, J. 2009. Leaf tensile properties of 11 resurrection plants differ among species in their response to drying. South African 12 Journal of Botany 75(1), 8-16.

13 Layton, B. E., Boyd, M. B., Tripepi, M. S., Bitonti, B. M., Dollahon, M. N., Balsamo, R. 14 A. 2010. Dehydration-induced expression of a 31-kDa dehydrin in Polypodium 15 polypodioides (Polypodiaceae) may enable large, reversible deformation of cell 16 walls. Am J Bot 97(4), 535-544.

17 Layton, B. E., Sastry, A. M. 2006. Equal and local-load-sharing micromechanical models 18 for collagens: quantitative comparisons in response of non-diabetic and diabetic rat tissue. Acta Biomater 2(6), 595-607.

20 Lin, T., Caspar, T., Somerville, C., Preiss, J. 1991. Mutants of Arabidopsis with altered regulation of starch degradation. The Plant Cell 95, 1181-1188. 
1 Lin, T. P., Caspar, T., Somerville, C., Preiss, J. 1988. Isolation and Characterization of a

2 Starchless Mutant of Arabidopsis-Thaliana (L) Heynh Lacking Adpglucose

3 Pyrophosphorylase Activity. Plant Physiology 86(4), 1131-1135.

4 Lindberg, J, Smith, R., Peethambaran, B. 2012. Effects of 14-3-3 lambda on the 5 biosynthesis of flavonoids in Arabidopsis thaliana. PLANTA MEDICA 78(11), 61113.

7 MacMillan, C., Mansfield, S., Starchurski, Z., Evans, R., Southerton, S. 2010. Fasciclin8 like arabinogalactan proteins: specialization for stem biomechanics and cell wall 9 architecture in Arabidopsis and Eucalyptus. The Plant Journal 62(4), 689-703.

10 Milwich, M., Speck, T., Speck, O., Stegmaier, T., Planck, H. 2006. Biomimetics and 11 technical textiles: solving engineering problems with the help of nature's wisdom. 12 American Journal of Botany 93, 1455-1465.

13 NASC 2009. The Nottingham Arabidopsis Stock Centre (NASC). University of $14 \quad$ Nottingham.

15 Park, Y., Cosgrove, D. 2012. Changes in cell wall biomechanical properties in the 16 xyloglucan-deficient xxt1/xxt2 mutant of Arabidopsis. Plant Physiology 158, 465$17 \quad 475$.

18 Peña, M., Ryden, P., Madson, M., Smith, A., Carpita, N. 2004. The galactose residues of 19 xyloglucan are essential to maintain mechanical strength of the primary cell walls 20 in Arabidopsis during growth. Plant Physiology 134, 443-451.

21 Peng, Y., Zhang, J., Cap, G., Xie, Y., Liu, X., Lu, M., Wang, G. 2010. Overexpression of 22 a PLDa1 gene from Setaria italica enhances the sensitivity of Arabidopsis to 23 abscisic acid and improves its drought tolerance. Plant Cell Reports 29, 793-802. 
1 Pigliucci, M. 2002. Ecology and evolutionary biology of Arabidopsis. The Arabidopsis

2 Book. C. Somerville and E. Meyerowitz. online, pp.

3 Polizeli, M., Rizzatti, A., Monti, R., Terenzi, H., Jorge, J., Amorim, D. 2005. Xylanases

4 from fungi: properties and industrial applications. Applied Microbiology and $5 \quad$ Biotechnology 67, 577-591.

6 Popper, Z. 2008. Evolution and diversity of green plant cell walls. Current Opinion in $7 \quad$ Plant Biology 11, 286-292.

8 Price, J., Laxmi, A., St. Martin, S., Jang, J.-C. 2004. Global transcription profiling reveals 9 multiple sugar signal transduction mechanisms in Arabidopsis. The Plant Cell 16, $10 \quad 2128-2150$.

11 Purdue 2009. 101 Ways to Grow Arabidopsis [online]. Purdue University, Department of 12 Horticulture \& Landscape Architecture.

13 Radhamony, R., Anand, M., Srinivasan, R. 2005. T-DNA insertional mutagenesis in 14 Arabidopsis: a tool for functional genomics. The Electronic Journal of $15 \quad$ Biotechnology 8(1), 82-106.

16 Reiter, W. 2002. Biosynthesis and properties of the plant cell wall. Current Opinion in $17 \quad$ Plant Biology 5(6), 536-542.

18 Reiter, W., Chappie, C., Somerville, C. 1993. Altered growth and cell walls in a fucose19 deficient mutant of Arabidopsis. Science 261(5124), 1032-1035.

20 Reiter, W. D., Chapple, C., Somerville, C. R. 1997. Mutants of Arabidopsis thaliana with 21 altered cell wall polysaccharide composition. Plant Journal 12(2), 335-345. 
1 Rolny, N., Costa, L., Carrion, C., Guiamet, J. 2011. Is the electrolyte leakage assay an unequivocal test of membrane deterioration during leaf senescence? Plant Physiology and Biochemistry 49(10), 1220-1227.

4 Rösti, J., Barton, C., Albrecht, S., Dupree, P., Pauly, M., Findlay, K., Roberts, K., Seifert, G. 2007. UDP-Glucose 4-Epimerase Isoforms UGE2 and UGE4 Cooperate in Providing UDP-Galactose for Cell Wall Biosynthesis and Growth of Arabidopsis thaliana. The Plant Cell 19, 1565-1579.

8 Ryden, P., Sugimoto-Shirasu, K., Smith, A., Findlay, K., Reiter, W.-D., McCann, M. 2003. Tensile properties of Arabidopsis cell walls depend on both a xyloglucan cross-linked microfibrillar network and rhamnogalacturonan II-borate complexes.

12 Salinas, J., Sanchez-Serrano, J. 2006. Methods in Molecular Biology 323. Totowa, NJ, 13 Humana Press.

14 TAIR 2009. The Arabidopsis Information Resource (TAIR) [online]. The Ohio State 15 University.

16 Taiz, L., Zeiger, E. 2006. Plant Physiology. Sunderland, MA, Sinauer Associates, Inc.

17 Taylor, N., Scheible, W., Cutler, S., Somerville, C., Turner, S. 1999. The irregular

18 xylem3 locus of Arabidopsis encodes a cellulose synthase required for secondary

19 cell wall synthesis. The Plant Cell 11(5), 769-780.

20 Tinus, R. 2002. Using electrolyte leakage tests to determine lifting windows and detect 21 tissue damage. National Proceedings: Forest and Conservation Nursery 22 Associations - 1999, 2000, \& 2001. Proceedings RMRS-P-24, Ogden, UT. 
1 Vicré, M., Lerouxel, O., Farrant, J., Lerouge, P., Driouich, A. 2004. Composition and 2 desiccation-induced alterations of the cell wall in the resurrection plant 3 Craterostigma wilmsii. Physiologia Plantarum 120(2), 229-239.

4 Vincent, J. 1983. The influence of water content on the stiffness and fracture properties 5 of grass leaves. Grass and Forage Science 38, 107-114.

6 Vogel, J. P., Raab, T. K., Schiff, C., Somerville, S. C. 2002. PMR6, a pectate lyase-like 7 gene required for powdery mildew susceptibility in Arabidopsis. Plant Cell 14(9), $8 \quad 2095-2106$.

9 Zablackis, E., Huang, J., Müller, B., Darvill, A., Albersheim, P. 1995. Characterization of 10 the cell-wall polysaccharides of Arabidopsis thaliana leaves. Plant Physiology $11 \quad 107,1129-1138$.

12 Zykwinska, A., Ralet, M.-C., Garnier, C., Thibault, J. 2005. Evidence for in vitro binding 13 of pectin side chains to cellulose. Plant Physiology 139, 397-407. 


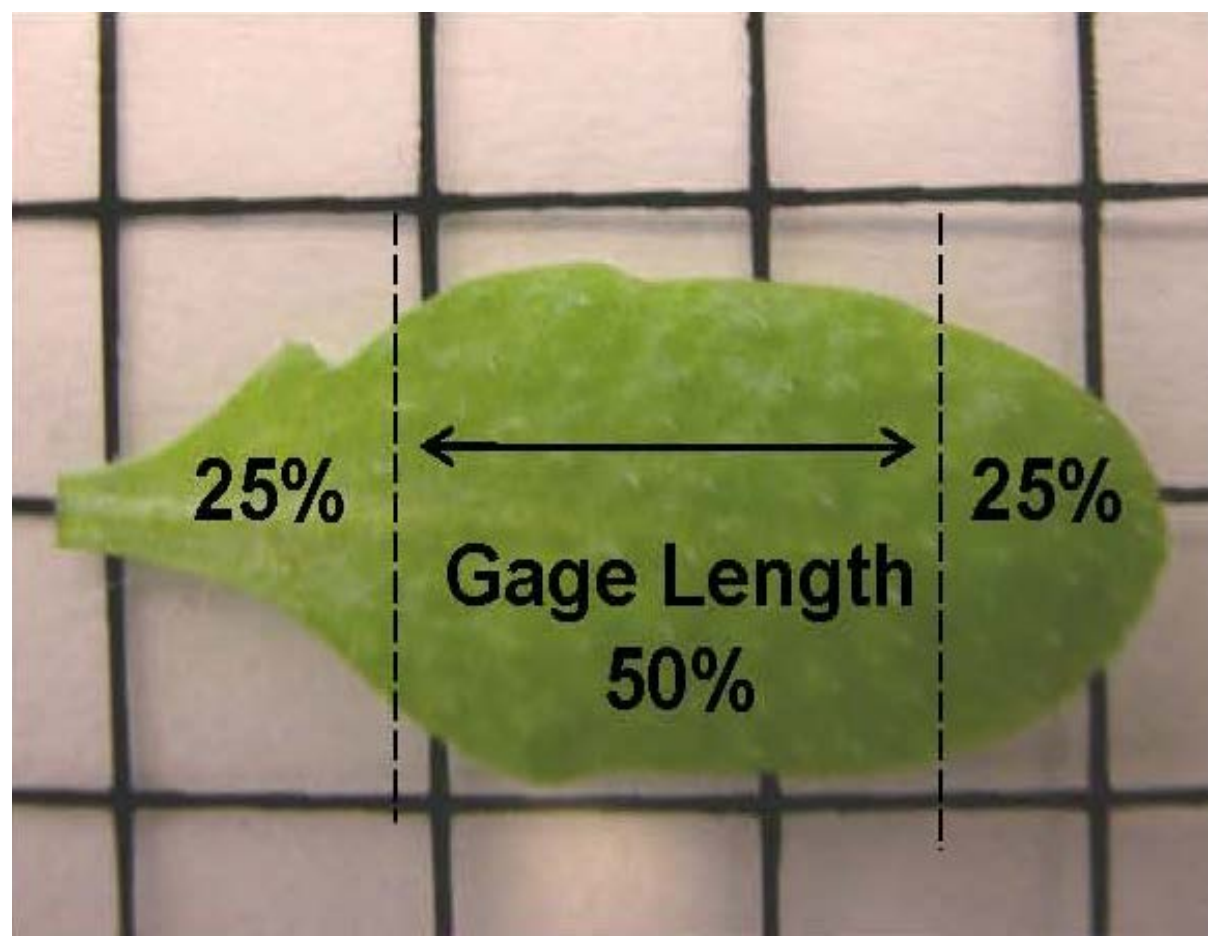

Figure 1: Example of leaf measurement and strategy for leaf clamping prior to mechanical testing. 


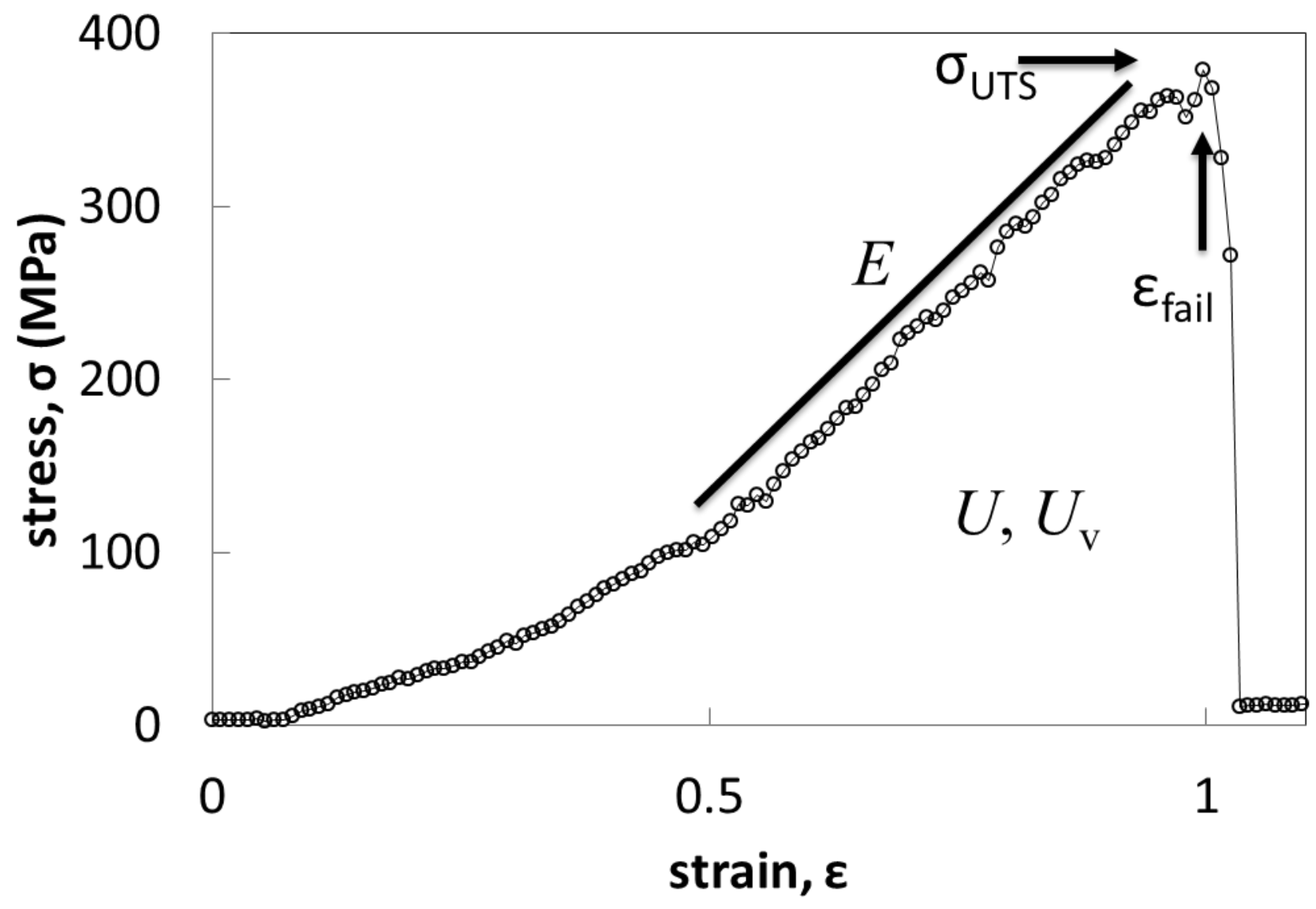

Figure 2: Representative stress-strain plot of hydrated mutant S120106 indicating five mechanical properties measured. Work to failure, $U$ and toughness, $U_{V}$ are represented by the area under the curve. Ultimate tensile strength $\sigma_{U T S}$ failure strain $\varepsilon_{\text {fair }}$ and tensile modulus, E are also shown. 

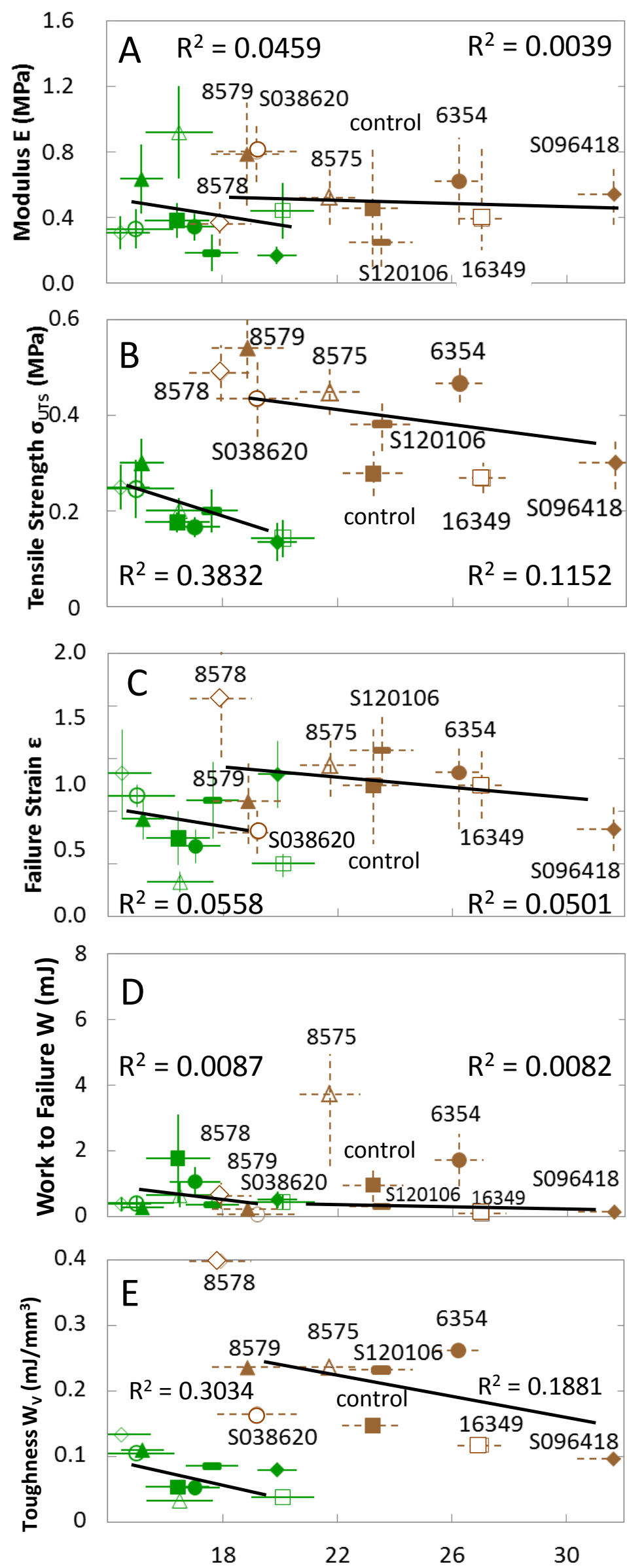

Conductance $s(\mu s) \quad$ Figure 3 
Figure 3: Mechanical properties plotted as a function of conductance for sugar-treated plants $\square$ untreated Col-0, $\bullet 6354, \triangle 8575, \diamond$ 8578, $\Delta$ 8579, $\square$ 16349, O S08620, $\diamond$ S096418, — S120106. Green represents hydrated specimens. Brown represents water-deprived specimens. Error bars represent \pm 1 SEM. $n=15$ for all measurements. 